\title{
Granular corneal dystrophy type II
}

INSERM

\section{Source}

INSERM. (1999). Orphanet: an online rare disease and orphan drug data base. Granular corneal dystrophy type II. ORPHA:98963

Type II granular corneal dystrophy (GCDII) is a rare form of stromal corneal dystrophy (see this term) characterized by irregular-shaped well-demarcated granular deposits in the superficial central corneal stroma, and progressive visual impairment. 